\section{MAIN TRENDS}

OF MILTARY SPACE ACTIVITY AT THE MODERN STAGE

Vladimir L. IVANOV

Doctor of Military Sciences, Professor, Advisor to the General Director of JSC "Khrunichev State Research and Production Space Center", Moscow, Russia. aqd@khrunichev.com

Mikhail I. MAKAROV

Doctor of Technical Sciences, Professor, first deputy director, scientific director of Research Institute of Space Systems niamed after A.A.A.Maksimov" - branch of
ISC "Khrunichev State Research and Production Space Center", Moscow, Russia, info@nitiks.com

Igor N. GOLOVĀNEV Candidate of Technical Science, senior researcher, advisor to the director of Research Institute of space systems named

and Production S
info@niiks.com

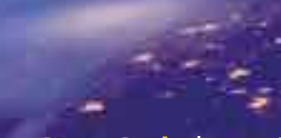
The political and military decisions of the USA d. The maily inctions of lea sp activity are revealed

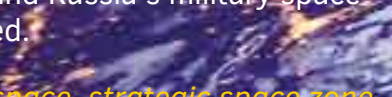

ОСНОВНЫЕ ТЕНДЕНЦИИ ВОЕННО-КОСМИЧЕСКОЙ ДЕНТЕЛЬНОСТИ НА СОВРЕМЕННОМ BTAIE

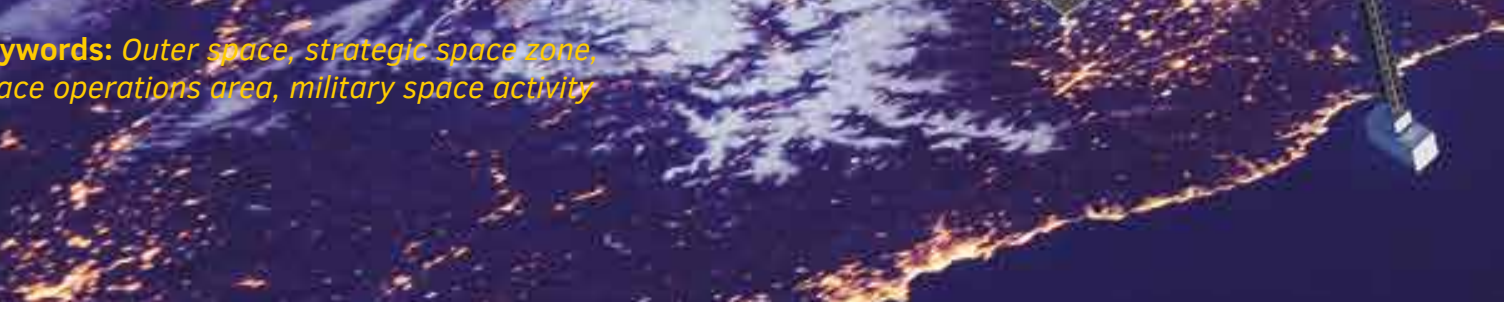




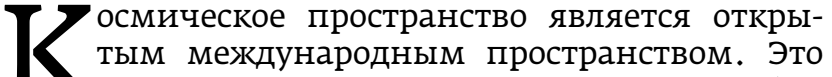
тым международным пространством. Это ные тела, открыто для исследования и использования всеми и в соответствии с межжународным правом не принадлежит национальному присвоеи их природные ресурсы являются общим достоя. вание осуществляются на благо и в интересах всех го человечества. Вся деятельность в космосе должна осушествляться в интересах поддержания мир и безопасности, а также развития сотрудничества Запрешен вывод на орбиту любых объектов с ядерным и любым иным оружием массового уничтожения (химическим, бактериологическим, радиологическим и др.). Луна и иные небесные тела используются исключительно в мирных целях Это закреплено в ряде международных договоров например в Договоре о принципах деятельности государств по испогьзованию космического про(подписан 27.01.1967), а также в Соглашении о дея(ельности государств на Луне и других небе деятелах (заключено в рамках ООН 18.12.1979). Космическое пространство доступно для использования всеми государствами земного шара, и в настоящее время на него не распространяются национальные законы ни одного из них.

По межжународному праву околоземное космическое пространство (ОЗКП) и космос в целом экстерриториальны и не привязаны к земной по верхности. Однако со стороны отдельных стран в частности США, уже сегодня проявляется желание игнорировать ранее принятые общечеловеческие нормы. Об этом свидетельствует фак том Трампом указа, закрепляющего право амальканцев на добычу космических ресурсов на Луне и противоречащего подписанному в 1979 году Соглашению о деятельности государств на Луне и других небесных телах. В Соглашении декларируются принципы исключительно мирного использования космоса и недопустимость претензий со стороны любого государства на распространение своего суверенитета на какое-либо небесное

На наш взгляд, указ Д. Трампа есть не что иное, как дальнейшее развитие и реализация космиче ской стратей СШа, определенной нижег денными документами и решениями.

В 1996 году президентом Б. Клинтоном была вве дена в действие директива PDD-NSC- 49/NSTC-8, в которой определены основные цели военно-кос

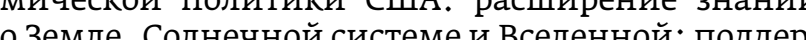
жание и укрепление национальной безопасности
США; повышение конкурентоспособности национальной экономики; расширение научных и технических возможностей; поощрение инвестиций тдельных штатов, направленных на использование ими космических средств и технологий расширение международного сотрудничесіва для продвижения интересов США в сфере внутренней и внешней политики и обеспечения националь-

Концепция Joint Vision 2020 - план развития вооруженных сил США до 2020 года, разработанный В 2002 году Объединенным комитетом начальнивсеобтемлюшего господства, готовность к проведению военех гпераций во всех областя оперативной деятельности в космосе, на море, на суше, в воздухе и информационном пространстве, Оче видно стремление США обеспечить военное господство в космосе.

В 2006 году президент США Дж. Буш - младший подписал космическую доктрину, определяюшую принцип оборонной и разведывательной деятельности в космосе, не допускающую ограничения срав США на сбор и использование информации с по ощь космических средств. Директивой са испо

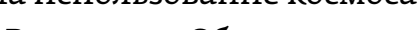

В 2009 году Объединенный комитет начальников штабов за несколько дней до инаугурации Барака ских операций, овал татируюшую готовность Сш тер формации, дезорганизации, сдерживанию и разрушению космической инфраструктуры противника, если она представляет угрозу безопасности США.

В декабре 2010 года Министерством обороны США жан «Всесторонний обзор космической стратегии". В документе освещены следующие основные задачи обеспечения национальной без-

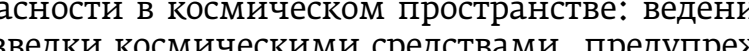
разедки космическими средствами, предупрежпечение спутниковой связи; космическое радионавигационное обеспечение; вывод полезных нагрузок в космическое пространство; эксплуатация космических систем; контроль обстановки В космосе, управление космической деятельноКосмос для США становится прочным фундаментом для сша становится прочным фундасил. С 2011 года сделаны шаги такой трансформации по созданию динамичной глобальной информационной системы (ГИС), которая, по замыслу американских стратегов, должна усилить действенность информации и повысит эффективность реализации военно-космических

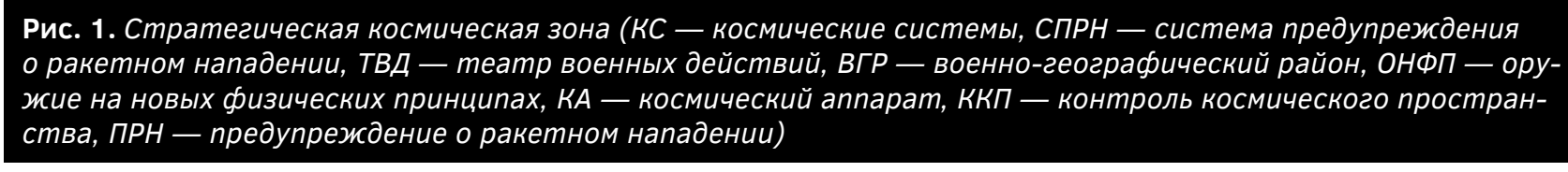

\section{Ближняя}

операционная зона

К.

(10:

стировки,

Всего $60 \%$

Средняя

операционная зона

$-20000 \mathrm{kM} /$

KC: навигац
Всего $10 \%$

\section{Дальняя \\ операционная зон \\ КС: СПРН, Связи, \\ боевого управления, \\ ретрансляции, геофи- \\ зического обеспечения \\ разведки
Всего $\mathbf{3 0 \%}$}

СКЗ как сфера ведения боевых

действий

Глобальный пространственный размах бое-

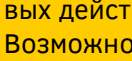

Созможность воздействия космическими
средствами по объектам на любых ТВД и

любых видов оружия, включая ОНФП.

Построение группировок в разведыва-

тельно-ударные комплексы, включающие

ударные
средства.

программ. Создание ГИС - это реализация информационной стратегии США, призванной обеспечить господство в "море информации" и в космосе. ГИС создавалась как в интересах Пентагона, так и для всего разведывательного сообщества США. ГИС - это глобальная многосоставная информационная система, обеспечивающая высокий уровень интеграции вооружений, разведки и военного потенциала, достаточный для чивает всем военным базам и боевым платформам - кораблям, самолетам, космическим ап-
Наземние элементы СКз - центры и пункты управ-

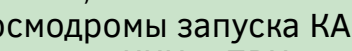
- средства ККН и ПРН - абонентская аппаратура потребителей комплексы;

арсеналы и базы хранения; - районы падения фрагракет-носителей. информационным ресурсам во всех местах их дислокации, поддерживает решение всех задач и выполнение стратегических, оперативных,

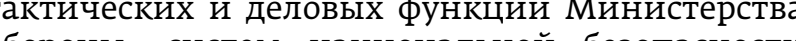
безоласности в принадлежит Агентству передовнх Research Projects Agency, DARPA) Министерства обороны США. 
Одно из ключевых направлений современной американской военной политики заключается В обеспечении информационно-космического доминирования США путем:

- обеспечения свободы действий США в информационном и космическом пространстве;

- создания сверхмощного закрытого космичекого интернета;

- предотвращения нарушения работы интернещиты космического информационного трафика.

17 июля 2017 года палата представителей Конгресса США приняла законопроект по созданию космического рода войск.

В марте 2018 года президент Д. Трамп заявил ноименным министерством. Тогда он назвал космос таким же «полем для битвы», каким являются суша, воздушное и морское пространства.

В августе 2018 года американский вице-президент М. Пенс обнародовал общий план формирования военно-космических сил.Д. Трамп поддержал выступление своего заместителя через Twitter: «Космические силы, вперед

В конце февраля 2019 года Д. Трамп подписал меморандум, в соответствии с которым новая военно-административная структура представленкак нечто среднее между отдельным родом войс США и видом вооруженных сил. Администра ция Д. Трампа запустила функционирование косСША аттивизировало Свои усилия по превраше Нию космоса в реальный тезтр военных действий. 21 августа 2020 гопа бнли успешно завершены 21 августа 2020 гдда были успешно завершень в соответствии с программой подготовки и обучения специалистов в области ведения боевых действий в окодоземном космическом пространстве утвержденной 24 июля 2020 года.

10 августа Космическое командование США соббщило о выходе в свет первой доктрины Космических сил под названием "Космическая мощь», в которой определены главные цели и задачи боевых действий в космосе, а также сформулированы основные направления их реализации.

Мероприятия США по информационно-косми ческому доминированию в мире, созданию военно-космических сил не остаются без внимания со стороны российских военных и гражданских ученых, специалистов, работающих на предприятиях ракетно-космической промышленности, военно-организационных структурах Минобороны $\mathrm{P} \Phi$, а талеке в высших уиеных заведениях дров для космической деятельности в России. Ими выполнено немало открытых аналитических работ, раскрывающих взгляды США, ведущих стран в военных целях [1-11]. Разработаны теоретические положения космического пространства как сферы вооруженной борьбы, а также сформули рованы определения категорий "стратегическа космическая зона» (СК3) и "космическая операционная зона» (КО3). Раскроем сущность и характе

С той или иной глубиной и детализацией рас крытия сущности стратегической космической даны в публикачиях $[1,4,5,6]$. Интегральное даны в публикациях $[1,4,5,6]$. Интегрально

стратегическая космическая зона - околоземно осмическое пространство и выделенные для осуповерхности Земли в условно определенных геостратегических границах, где проявляются или могут затрагиваться национальные интересы России в космосе.

В СК3 условно выделяют три космические опе рационные зоны (КО3) (рис. 1): ближнюю, средию и дальнюю $[1,5]$. Ближняя зона простирается дипазоне высот от 100 до 2000 км, в ней развертываются и функционируют орбитальные груп. морской навигации, контроля космического про-

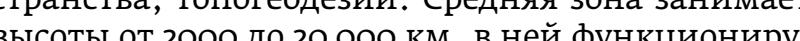
ют космические аппараты систем радионниру ции. Для дальней зоны характерны высоты свыше 20 ооо км с функционированием спутниковых систем обнаружения пусков баллистических ракет связи и боевого управления, ретрансляции, разведки и метеорологии.

Ведущие позиции в использовании КО3 занимают США, которые путем целенаправленного финансирования военных космических программ смогли добиться технологического превосходства над Многими странами мира, и они стремятся

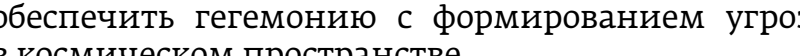
Военно-космическими программами сегодня располагают не только США, но и другие ве дущие страны (Канада, Великобритания, Германия, Франция, Китай, Индия, Израиль) [1] При этом самостоятельное геополитическое . логическим внезапностям (создаюшим угроз в космосе и из космоса), включая демонстрачию своих возможностей в этой стремительно развивающейся сфере политического, информационного и вооруженного противоборства.
Рис. 2. Подәержание стратегической стабильны
средств (СБУ - система боевого управления)

^ Стратегическая разведка в интересах оценки военноэкономического потенциала вероятного противника

$\star$ Контроль соблюдения договоров и соглашений в области огранич

Ł Стратегическая (магистральная) связь и боевое управлени:

Ł Оперативные глобальные телекоммуникации в интересах получения и передачи специнформации

$\star$ Раннее предупреждение о ракетном, воздушном и косм нападении

$\star$ Формирование баз данных спектральных признаков овтоматического дешифрирования космоснимков;

‡ Создание и обновление топо- и цифровых карт рельефа и местности по любому району земного шара, включая трехмерные цифровые модели для систем стратегическона глубину до нескольких метров (в сине-зеленой зоне спектра);

Ł Создание систем объектовой, региональной и глобальной противоракетной обороны:

$\star$ Оперативная доразведка стратегически важных ТВД.

Для поддержания стратегической стабильности с использованием космических сил и средств реявпяются: раннее предупреждение о рахетном воздушном и космическом нападении, стратегическая разведка (доразведка) объектов и территорий, связи и боевое управление стратегическими ядерными силами (СяС), демонстрация возможностей создания систем противоракетной обороны, а также контроль соблюдения договоров и соглашений в обласи ограничений ядерных сратегических вооружений и космоса.

В связи с принятием президентом Д. Трампом решения о создании полноценных космических войск США целенаправленно занимаются разработкой и подготовкой к развертыванию в около-

• оружия наземного и воздушного базирования,

- оружия наземного и воздушного базирования, лазеры, чтобы «ослепиты", вывести из строя приборы и нарушить систему спутников:

- оружия космического базирования, которое действует против других космических систем;
- космического оружия, поражающего цели

Рассмотрим основные аспекты военно-космиче(

С точки зрения парирования угроз вероятного противника, а также формирования стратегии равтики стедует үчитывать стедуюшие основны тендени сли доенНО-госмической деятельности США и Китая (рис. 3):

1. Интеграция спутниковых систем в единую информационно-телекоммуникационную дарных систем и высокоточного оружия в будущих войнах. Вооруженные конфликты XXI века предполагают проведение сетецентрических операций, основанных на комплексном использовании космических средств разведки, связи, боево2. Развитие многоспутниковых систем на базе малых космических аппаратов (МКА). В условиях того, что США, так же как и Россия, зависят от воз- 
можности использования космоса, они реально рассматривают его в качестве сферы вооруженной борьбы, проводя в жизнь новые подходы к организации живучести и гибкости своей орбитальной группировки. На фоне впечатляющих успехов использования коммерческих МКА (от 1 до 500 кг)
Минобороны США рассматривает их применение в качестве средств оперативной разведки и свяи, рекогносцировки и управления на ТВД, предупреждения о нападении, а также как инструмен восстановления (нарашивания) группировок.

3. Практическа отработка вопросов боевого при3. Практическая отрабопа вопосов боевого прии из космоса, включая беспилотные авиасионно-космические системы многоразового использования и гиперзвуковые летательные аппараты.
На сегодняшний день Китаем и Соединенными Штатами проведены испытания противоспутникового оружия по реальным мишеням в космосе Принципиально не ставя задачу создания группироки противоспутниковой борьбы (ПСБ) орбитальвали возможность прямого перехвата КА в любой точке орбиты с использованием морских противоракет ПРО. Противоспутниковым Нотенциалом обладает уже развернутый наземный эшелон протиПри этом планируется отрабатывать технологии решения задач ПСБ с использованием наземных средств радиоэлектронной борьбы (РэБ)

Военно-космическая деятельность России является одним из
литики (рис. 4).

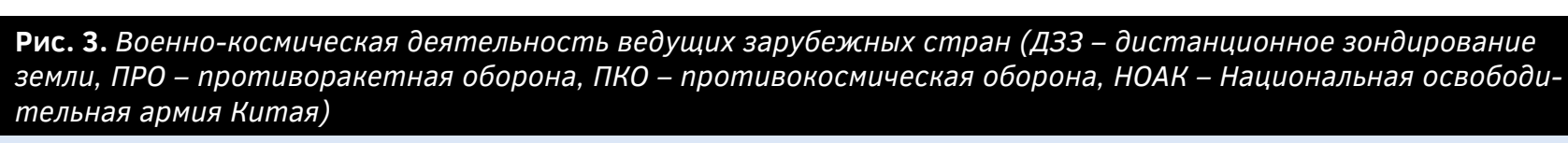

ОСНОВНЫЕ ТЕНДЕНЦИИ ВКД В XXI ВЕКЕ

Интеграция спутниковых систем в единые
информационно-телекоммуникационные сети

Расширение использования коммерческих космических систем в военных конфликтах
миротворческих операциях (связь, ДЗ3)

Развитие многоспутниковых систем на базе

спутников малых форм (МКА)

Размещение на коммерческих спутниках полезных нагрузок военного назначения

Эффективный контроль космического пространства и разведки космической обста-

ДЕЙСТВУЮЩИЕ НОРМАТИВНЫЕ ДОКУМЕНТЫ МО США «Национальная космическая действие директивой президента, июнь 2010); «Стратегия национальной (утверждена министром обороны и директором национальной разведки, январь 2011)

«Космическая политика» (директива заместителя министра обороны по вопрос «Космические операции»
(наставление Комитета начальников штабов, май 2013) ния средств вооруженной
и из космоса (ПРО, ПКО)

СПЕЦИАЛИЗИРОВАННЫЕ ВОЕННЫЕ СТРУКТУРЫ

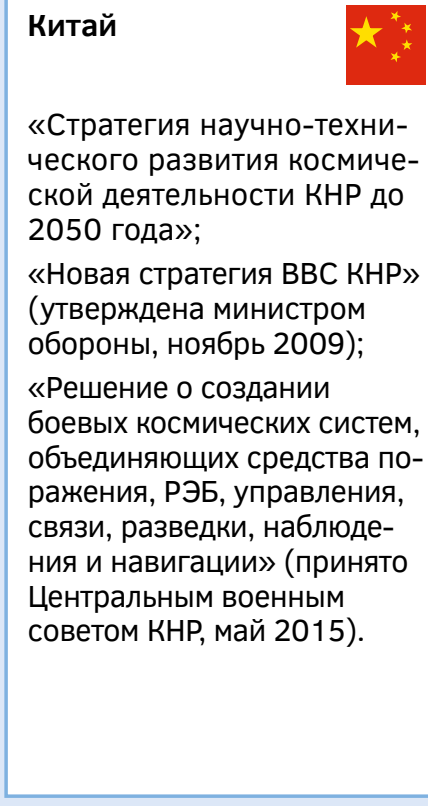

\begin{tabular}{|l|}
\hline объединенное космическое \\
командование функциональной \\
космической компонентой \\
Применение космических \\
средств разведки космической \\
обстановки, их интеграция с \\
системами мониторина кибер- \\
пространства и другими разве- \\
дывательными системами
\end{tabular}

Силы стратегической поддержки НОАК (вид ВС)

Ведение военных действий в организации и функционирования единой разведывательно-информационной среды

Рис. 4. Военно-космическая деятельность России (ВВT - вооружение и военная техника)

Внешняя военная опасность, связанная с намерением противника: Łразмещение оружия в космосе;

Łиспользование информационных и коммуникацион-
ных технологий в военно-политических целях

Основные военные угрозы: ऋнарушение функционироПРН и ККП:

$\star$ массированное примен

$\star$ одновременное воздействие в глобальном информационном, возду ИНом И

‡усиление централизации жием в результате переход от строго вертикальной системы управления к глобальным сетевым автоматизированным системам.

Основные задачи РФ по щению военных конфликтов: ^противодействие попыткам обиться военного превосходства путем развертывакосмосе;

$\star$ «заключ « заключение международщении повора о предотвравидов оружия в космическом пространстве;

$\star$ согласование в рамках о0 элогласование в рамках регулирования безопасного осуществления космической деятельности;

*укрепление потенциала РФ в области мониторинга объекВв и событий в околоземном постранстве.
Задачи ВС мирного времени: ৯своевременное предупреждение о воздушном и космическом нападении и обеспечение готовности к его отражению, оповещение органов военного управления, войск (сил) о во-

Łразвертывание и поддержание в СКЗ обеспечивающих деятельность

Задачи оснащения ВC BBC $\star$ создание новых образцов Ввт, систем связи, разведки и

๙ создание базовых информационно-управляющих систем оружия и комплексами средств автоматизации органов управления от стратегического до тактического масштаба.
Состояние военно-космической деятельности РФ должно отвечать потребностям эффективного реагирования на вызовы, риски и угрозы современного мира, опираясь на [1]:

- положения, констатирующие внешнюю военную опасность, вызванную "намерением вероятного противника разместить оружие в космосе», а также "использовать информационные и коммуникационные технологии в военно-политических целях»; основные военные угрозы, сре ди которых - «нарушение функционирования систем предупрежқдения о ракетном нападении (ККП): и контровя космического пространства диоэтектронной борьбы (РЭБ); оружия на новых физических принципах (ОНФП); одновременное воздействие в глобальном информационном и воздушно-космическом пространствах; усиление централизации управления войсками и оружием в результате перехода от строго вертикальной системы управления $\mathrm{K}$ глобальным сетевым автоматизированным системам;

- «основные задачи РФ по сдерживанию и предотвращению военных конфликтов. Противодей- ства путем развертывания систем стратегической и размещения оружия в космосе; заключе作 в космосе любых видов оружия в сомласование в рамках ООН элементов нормативного регулирования безопасного осущест. и событий в околоземном пространстве»;

- задачи ВС мирного времени: «своевременное педупреждение о воздушном и космическом нанию; оповешение органов военного управления войск (сил) о военных опасностях и угрозах; "развертывание и поддержание в СК3 обеспечивающих деятельность Вооруженных сил России орбитальных группировок»;

- "создание новых образцов вооружения и воки и управления, РэБ; базовых информационно-управляющих систем и их интеграцию системами оружия и комплексами средств автоматизации органов управления от оперативно-стратегического до тактического масштаба». 
Целью военно-космической деятельности России необходимо считать сохранение независимости страны в военно-прикладном использовании космоса за счет создания и эфФективного примене ния целостной, функционально интегрированной В войска системы космического вооружения. Система должна реализовывать оперативные возможоости космических сил и средств, гарантирующих обеспечение обороны й безопасносии прй условии оетно-космической промышленности и развития ориентированного на импортозамешение, отече ственные инновационные технологии.

$\mathrm{K}$ приоритетам военно-космической деятельноК приорит направления сосредоточения усилий государства которые позволят гарантированно обеспечить достижение цели ВКД на основе как компетенций, отвечающих современным вызовам и угрозам, так и струкур, позволяющих эти компетенции реализовать. В числе таких приоритетов:

* дальнейшая централизация военно-космической деятельности в структуре органов военного управления стратегического уровня, отвечающая как ее явно выраженному межвидовому характеру, так и направленности на решение разведнев страны;
разитильн-экономического
* возврат к системному подходу в вопросах создасредств космического вооружения (система космического вооружения) и их применения (военно-космическая концепция), развитие соответ срующих организационных структур в системе орген космичестика воссоздания институга «системы и реализорать переход к передовым тифровим интеллектуальным роботизированным произ водственным технологиям, новым материалам и способам конструирования, средствам обработки больших объемов данных, машинного обучения и искусственного интеллекта, в максимальной степени исключающих научно-технические внезапности, связанные с возможностью завоевания противником господства в космосе;

* оперативное оборудование стратегической космической зоны и поддержание (развитие) космиче ской инфраструктуры, обеспечивающей гарантированное и эффективное применение космических средств военного и двойного назначения;

* обеспечение гарантированного доступа России в космическое пространство со своей территории, развитие орбитальных группировок различного назначения, создание и внедрение космических чения безопасности.

\section{ЗАКЛЮЧЕНИЕ}

1. Принятые международные соглашения и договоры по космической деятельности регламентируют пространство доступно для использования всеми государствами земного шара, и на него не распространяются национальные законы ни одного из них.

2. За последние два десятилетия в США приняты и реализуются военно-политические решения (концепции, директивы, доктрины, стратегии и пр.), целями которых являются:

- создание глобальной многоуровневой информационно-космической системы, обеспечивающей доминирование и господство в космосе, высокий уровень интеграции вооружений, разведки, военного потенциала, достаточного для ведения сетецентрических войн;

- создание космических войск для решения стратегических, оперативных и тактических задач Министерства обороны США, систем национальной безопасности в мирное и военное время.

3. Рассмотрены основные аспекты военно-космической политики ведущих зарубежных стран, а также

4. С целью поддержания стратегической стабильности в мире описаны мероприятия и задачи, выполняемые Россией с применением национальных космических сил и средств. Сформулированы при-

\section{Литература}

1. Иванов В.Л., Голованёв И.Н., Макаров М.И., Щербаков Н.Б. Космос - сф $220 \mathrm{c}$.

Mar. $M$. нов В.Л. Космическое информационно обеспечение боевых действий вооруженных сил - основные тенденции и перспективы развития // Стратегичес 3. Савиных В.П. Космическая сфера

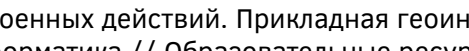
и технологии. 2015. № 3. С. $96-102$. 4. Васильев Ю. Взгляды военно-политического руководства КНР на испольбование космоса в военных целях // Зарубежное военное обозрение. 2019

5. Васильев Ю. Взгляды ведущих стра военных целях // Зарубежное воен . Стратегическая космическая зон (СК3) [электронный ресурс] // Энциклопедия ракетных войск стратегического Министерства обороны РФ. URL: https/// encyclopedia.mil.ru/encyclopedia/
dictionary/details.htm?id=10376@ dictionary/details.htm?id=10376@ morfDictionary
$01.09 .2020)$.

7. Дорофеев В. США: использование ва в военных целях // Зарубежн С. $43-48$

8. Анализ космической стратегии США [Электронный ресурс] // ultimaguardian Живой журнал. 24.12.2009. URL: https:// ultimaguardian.livejournal.com/112662.

9. Макаренко С и использование космического пространствавание в военных целях: современное состояние и перспективы развития систем информационно-космического обеспечения и средств вооружения // Системы управления, связи
С. $161-213$.

10. Длугоцкий Д. Американские программы развития космических систем наблюдения Земли в инфракрасном диапазоне // Зарубежное военное обо11. ческий мониторинг и стратегическая стабильность в современных условиях // Стратегическая стабильность. 2019. № 3. С. $19-24$.
References

UanoV V.L., Golovanev I.N

sfera vooruzhennorbakov N.B. Kosmos S, 2019. $220 \mathrm{p}$.

. Makarov M.I., Golovanev I.N. vespechenie boevykh deystviy vooruzhennykh sil - osnovnye tendentsi i perspektivy razvitiya. Strategicheskay i 3. Savinykh V.P. Kosmicheskaya
sfera voennykh deystviy. Prikladnat geoinformatika. Obrazovatel'nye resursy i tekhnologii, 2015, no. 3, pp. $96-102$. 4. Vasil'ev Yu. Vzglyady voennopoliticheskogo rukovodstva KNR na spol'zovanie kosmosa v voennykh tselyakh. Zarubezhnoe voennoe obozreni

. Vasil'ev Yu. Vzglyady vedushchikh voennykh tselyakh. Zarubezhnoe voennoe obozrenie, 2016, no. 1, pp. 62 - 68. 6. Strategicheskaya kosmicheskaya zona (SKZ). Entsiklopediya raketnykh voysk strategicheskogo naznacheniya. Voennay RF. Available at: https://encyclopedia mil.ru/encyclopedia/dictionary/details. htm?id=10376@morfDictionary (Retrieva date: 01.09 .2020 ).

7. Dorofeev V. SShA: ispol'zovanie Kosmosa v voennykh tselyakh. no. $5-6$, pp. $43-48$. 8. Analiz kosmicheskoy strategii SShA. ultimaguardian LiveJournal, 2009 . December 24. Available at: https:// ultimaguardian.livejournal.com/112662. 9. Makarenko S.I. Ispol'zovanie
kosmicheskogo rostranstva v voennykh tselyakh: sovremennoe sostoyanie i perspektivy razvitiya sistem informatsionno-kosmicheskogo obespecheniya i sredstv vooruzheniya. Sistemy upravleniya, svyazi i
2016, no. 4 , pp. $161-213$. 10. Dlugotskiy D. Amerikanskie sistem nablyudeniya Zemili v infrakrasno diapazone. Zarubezhnoe voennoe
obozrenie, 2019, no. 12, pp. 52 - 59 . 11. Volkov A.E., Zaytsev M.A. strategicheskaya stabil'nost' $v$ sovremennykh usloviyakh. Strategicheskaya stabil'nost', 2019 , no. 3 ,
pp. $19-24$.

\section{(ఠ) Иванов М.Л., Макаров М.И., Голованёв И.Н., 202}

История статьи: Поступила в редакцию: 21.08.2020

модератор: Плетнер К.В. Конфликт интересов: отсутствует

Аля цитирования:

Иванов М.Л., Макаров М.И., Голованёв И.Н.
основные тенденции военно-космической деятельности на современном этапе // Воздушно-космическая сфьера. 2020. № 3. 